\title{
Residual Life Assessment of Water Distribution System Through Analysis of Cast Iron Pipes
}

\author{
Lee Hyun-Dong ${ }^{1,2, \dagger}$ and Shin Hong-Cheol ${ }^{1}$ \\ ${ }^{1}$ University of Science and Technology, Construction and Environment \\ Engineering. 217, Gajeong-ro, Yuseong-gu, Daejeon, Republic of Korea \\ ${ }^{2}$ Korea Institute of Civil Engineering and Building Technology, Environment and \\ Plant Engineering Research Institute Daehwa-dong 283, Goyangdae-Ro, \\ Ilsanseo-gu, Goyang-si, Gyeonggi-do, Republic of Korea \\ \{hdlee,hcshin\}@kict.re.kr \\ ${ }^{\dagger}$ Corresponding Author
}

\begin{abstract}
Water distribution system is the facility to provide water stably. But sometimes, water leakages in water distribution systems cause enormous economic damage and destabilize such systems. To estimate residual life in this study, a total of 34 cast-iron pipes including ductile cast-iron pipes from differing laying environments in P city were used. After assessment, we determined that an improvement plan based on a residual life assessment was more efficient than a traditional plan based on laying year.
\end{abstract}

Keywords: Residual life, Water distribution systems, Leakage, Corrosion rate, ShotBlasting

\section{Introduction}

Water distribution system is the facility to provide water stably. In Korea, the 2013 Water Supply Statistics, published by the Ministry of Environment in 2014, show that, of the total annual domestic water supply of 6,159 million $\mathrm{m}^{3}$, a leakage of 656 million $\mathrm{m}^{3}$ $(10.7 \%)$ occurred. Water leakages in water distribution systems cause enormous economic damage and destabilizes such systems. Corrosion and aging are the main reasons for leakages from pipes laid under the ground. The outside of underground water supply pipes comes into contact with soil, while the inside is in contact with treated water; therefore, the pipe is affected by the friction caused by the elemental compositions of the soil and water, which are associated with physical and chemical changes. 2 Large differences in corrosion rates are observed according to the body type of the pipe, especially DCIPs, many of which have been recently laid, as the CML plays a major role in the prevention of internal corrosion during the initial year. Beyond the initial year, though, the neutralization of the CML tends to lead to a more accelerated rate of internal corrosion rate.

Through an evaluation of the internal and external residual thicknesses, a residual life assessment can minimize leakages caused by internal and external corrosion; however, a study on predicting the residual life of a water supply pipe through a residual thickness assessment in the domestic context found that corrosion scarcely progressed. This study therefore evaluated residual thickness according to the laying year of the pipe and corrosion rates by collecting pipes from both domestic and metropolitan contexts. The corrosion penetration time of the pipe was assessed to estimate the residual life for the purposes of an improvement plan. 


\section{Materials \& Method}

\subsection{Pipeline Collection}

To estimate the residual life of CIPs in domestic and metropolitan contexts, 34 CIP and DCIP samples from different laying environments were collected in P city. The regional statuses of the collected pipes are shown in Table 1. As shown in Table 1, most of the pipes $(n=21)$ were laid from 1976 to 1985 , the diameters of most of the pipes are in the $100 \mathrm{~mm}^{-} 200 \mathrm{~mm}$ range, and most were buried in residential or commercial areas. The average water pressure is in the $1 \mathrm{kgf} / \mathrm{cm}^{2} \sim 5 \mathrm{kgf} / \mathrm{cm}^{2}$ range and the maximum water pressure is in the $3 \mathrm{kgf} / \mathrm{cm}^{2} \sim 7 \mathrm{kgf} / \mathrm{cm}^{2}$ range.

Table 1. No. of Pipe Samples Collected

\begin{tabular}{|c|c|c|c|c|c|c|}
\hline NO. & Samples & $\begin{array}{l}\text { Pipe } \\
\text { type }\end{array}$ & $\begin{array}{c}\text { Laying } \\
\text { year }\end{array}$ & $\begin{array}{c}\text { Pipe } \\
\text { diameter } \\
(\mathrm{mm})\end{array}$ & $\begin{array}{c}\text { Maximum } \\
\text { water pressure } \\
\left(\mathrm{kgf} / \mathrm{cm}^{2}\right)\end{array}$ & Laying areas \\
\hline 1 & P-A-02 & CIP & 1968 & 200 & - & Road \\
\hline 2 & P-B-01 & CIP & - & 200 & $5(3.5)$ & Coastal \\
\hline 3 & P-B-02 & CIP & 1980 & 150 & $5(3)$ & Coastal \\
\hline 4 & P-B-03 & CIP & 1966 & 100 & $5(2)$ & Commercial \\
\hline 5 & P-B-05 & CIP & 1979 & 150 & $5(2)$ & Coastal \\
\hline 6 & P-B-06 & DCIP & - & 250 & $5(3)$ & Coastal \\
\hline 7 & P-C-03 & CIP & 1981 & 150 & - & Road \\
\hline 8 & P-C-04 & CIP & 1975 & 80 & - & Road \\
\hline 9 & P-D-01 & CIP & 1973 & 200 & - & Residential \\
\hline 10 & P-D-03 & CIP & 1974 & 200 & - & Road \\
\hline 11 & P-D-05 & CIP & 1978 & 150 & - & Road \\
\hline 12 & P-D-08 & CIP & 1976 & 150 & - & Commercial \\
\hline 13 & P-D-09 & CIP & 1983 & 100 & - & Commercial \\
\hline 14 & P-D-11 & CIP & 1979 & 150 & - & Commercial \\
\hline 15 & P-D-13 & CIP & 1973 & 200 & - & Residential \\
\hline 16 & P-E-02 & CIP & 1982 & 300 & $7(5)$ & Commercial \\
\hline 17 & P-E-04 & CIP & 1979 & 200 & $7(3)$ & Commercial \\
\hline 18 & P-E-05 & CIP & 1982 & 250 & $7(5)$ & Residential \\
\hline 19 & P-E-10 & DCIP & 1983 & 100 & $7(5)$ & Residential \\
\hline 20 & P-F-01 & CIP & 1977 & 300 & $4(1)$ & Commercial \\
\hline 21 & P-F-03 & CIP & 1979 & 100 & $6(3)$ & Residential \\
\hline 22 & P-F-09 & CIP & 1977 & 200 & $4(2)$ & Road \\
\hline 23 & P-F-11 & DCIP & 1990 & 100 & $4(2)$ & Residential \\
\hline
\end{tabular}




\begin{tabular}{lllllll}
24 & P-F-13 & DCIP & 1985 & 100 & $3(1)$ & Residential \\
25 & P-F-14 & CIP & 1982 & 150 & $4(2)$ & Residential \\
26 & P-F-17 & CIP & 1995 & 100 & $4(3)$ & Residential \\
27 & P-F-18 & DCIP & 1995 & 100 & $4(2)$ & Residential \\
28 & P-F-19 & CIP & 1980 & 100 & $4(3)$ & Residential \\
29 & P-F-20 & CIP & - & 100 & $3(1.7)$ & Residential \\
30 & P-G-02 & CIP & 1981 & 100 & $7(5)$ & Residential \\
31 & P-H-3 & CIP & 1990 & 100 & $6(3)$ & Industrial \\
32 & P-H-4 & CIP & 1982 & 100 & $6(4)$ & Residential \\
33 & P-I-01 & DCIP & 1985 & 100 & $6(2)$ & Commercial \\
34 & P-I-06 & DCIP & 1985 & 200 & $7(3)$ & Commercial \\
\hline
\end{tabular}

\subsection{Method of Estimating Residual Life}

Assessing residual life from the physical aspects of a water supply pipe generally involves estimating the current residual thickness of a pipe by calculating the time until corrosion piercing, both internal and external, reduces the initial thickness of the pipe to 0 $\mathrm{mm}$. To estimate residual life accurately, it is therefore necessary to calculate the maximum corrosion depths from both the internal and external linings of the pipe, to correctly identify the location of the survey subject in the water distribution system, and to calculate the corrosion rate according to the laying year; it is then possible to divide the residual thickness by the maximum corrosion rate to determine residual life. The pipe shown in Figure. 1 is affected by internal and external corrosive rust and scales, and the pipe itself produced the graphitic corrosion products (GCPs). The disguised GCPs maintain the pipe shape, but it has no structural strength; the maximum internal and external depths must be taken after the removal of the GCPs to estimate the residual thickness.

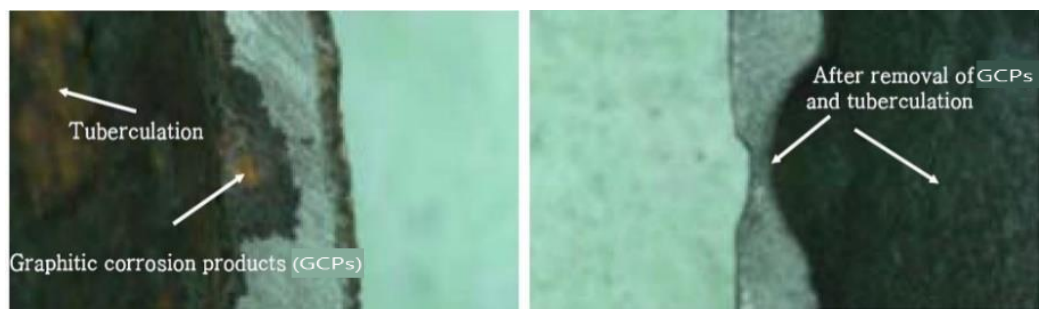

Figure 1. Pictures of CIPs before and after Shot-Blasting

2.1.1. Corrosion Depth: To measure the residual thicknesses of the CIPs and DCIPs in this study, a shot-blasting process was used to remove internal and external corrosion products and GPCs. After that, the initial pipe-wall thickness, internal maximum corrosion depth, and external maximum corrosion depth were estimated using a dial depth gage and a dial caliper gage. For the DCIPs, after the complete removal of the CML and the measurement of the maximum corrosion depth, the internal corrosion depth could only be measured using visual observation. 


\section{Residual Thickness}

Generally, the maximum internal and external corrosion depths of the collected pipes generated dissimilar occurrences at different points and did not represent the same vertical line. In determining the maximum residual thickness, it was necessary to use the maximum internal and external corrosion depth measurements and to adjust each depth in accordance with the maximum internal and external corrosion rates to accurately calculate the residual life. But, residual life cannot predict the risk of pre-leakage caused by penetration in cases where the entire water distribution system is very limited because the maximum corrosion depth is in or adjacent to the same line; therefore, in this study, even if an internal and external maximum corrosion rate dissimilarly occurred at a different point, it was considered to have occurred on the same vertical line. This can be interpreted in terms of the safety of this water distribution system, corrosion residual thickness equals except for sum of internal and external maximum corrosion depth thickness. At this stage, a residual thickness with a negative value was regarded as a residual thickness of 0 .

\section{Corrosion Rate}

$\left|\mathrm{R}_{\mathrm{t}}\right|=\mathrm{I}_{\mathrm{t}}-\left(\mathrm{E}_{\mathrm{mcd}}+\mathrm{I}_{\mathrm{mcd}}\right)$ Eq. (1) if $\left|\mathrm{R}_{\mathrm{t}}\right| \leq 0, \mathrm{R}_{\mathrm{t}}=0$, or $\left|\mathrm{R}_{\mathrm{t}}\right|>0, \mathrm{R}_{\mathrm{t}}=\mathrm{R}_{\mathrm{t}}$

Where, $R_{t}=$ Residual wall thickness of pipe, $\mathrm{mm}$

$\mathrm{I}_{\mathrm{t}}=$ Initial pipe wall thickness of pipe, $\mathrm{mm}$

$\mathrm{E}_{\mathrm{mcd}}=$ External maximum corrosion depth of pipe, $\mathrm{mm}$

$\mathrm{I}_{\mathrm{mcd}}=$ Internal maximum corrosion depth of pipe, $\mathrm{mm}$

It is known that, in general, the corrosion rate is in accordance with the laying year, but after the rate is initially rapid, the tendency of the rate will gradually decrease; therefore, it is virtually impossible to estimate the accurate corrosion rate because the measurement needs to cover a lengthy time period of numerous decades, from the time of laying up to the present time. For the CIPs and DCIPs in this study, the internal and external maximum depth measurements and laying years equate to different corrosion rates, but the same laying periods were used to calculate the internal and external maximum corrosion rates of each pipe.

$$
E_{\text {mer }}=\frac{E_{m e d}}{y} \text { Eq. (2) } I_{\text {mer }}=\frac{I_{m e d}}{y} \text { Eq. (3) }
$$

Where, $\mathrm{E}_{\mathrm{mcr}}=$ External maximum corrosion rate of pipe, mmpy

$\mathrm{I}_{\mathrm{mcr}}=$ Internal maximum corrosion rate of pipe, mmpy

$\mathrm{y}=$ Periods of laying, year

The internal corrosion of the DCIPs, however, does not proceed immediately after laying because of the CML that prevents internal corrosion. For DCIPs, the residual life will be useful in the development of an understanding of the internal corrosion process after CML neutralization occurs. For a DCIP residual life assessment, it is therefore necessary to estimate the CML neutralization rate using the following formula calculated except the neutralization proceeded totally (period of total CML neutralization), that is not going on corrosion and considering $\mathrm{t}_{\mathrm{n}}$ shown laying year of formula (3).

Where,

$$
I_{\text {mer }}=\frac{I_{\text {mod }}}{y-t_{\mathrm{n}}} \text { Eq. (4) }
$$

\footnotetext{
$t_{n}=$ Periods required of CML being $100 \%$ neutralization $=$ 10096-CML neutralization

Rate of CML neutralization $=\frac{\text { cML neutralization ratio }}{\text { periods of mpe laying }}$
}

The CML neutralization in Equation (4) was calculated as a percentage, whereby the neutralization thickness was divided by the total CML thickness and the neutralization rate was regarded as a constant according to time. In addition, when internal corrosion did not proceed on a CML surface, the internal corrosion rate was used to estimate the residual life by using the average maximum internal corrosion rate according to the laying year of each pipe collected in the area. 


\section{Residual Life}

In this study, the residual life of the CIPs and DCIPs was estimated by using the following formula for residual thickness and the internal and external maximum corrosion rates:

Where, $\mathrm{R}_{\mathrm{lf}}=$ Residual life of pipe, year

$$
R_{1 f}=\frac{R_{\mathrm{t}}}{\left[E_{\text {mer }}+I_{\text {mer }}\right]}=\frac{R_{t}}{c_{\mathrm{t}}} \text { Eq. (5) }
$$

$\mathrm{C}_{\mathrm{t}}=$ Maximum corrosion rate, mmpy

$\mathrm{R}_{\mathrm{t}}=$ Residual thickness of pipe, $\mathrm{mm}$

\section{Results and Conclusion}

\subsection{Internal and External Maximum Corrosion Depth}

In this study of the CIP and DCIP water supply pipes that were collected from P city, the internal and external maximum corrosion depths and residual thicknesses are shown in Table 2, and the internal and external maximum corrosion depth distribution according to the laying year are shown in Figure. 2. The internal maximum corrosion depth of the CIPs was associated with variations in the initial pipe thickness from $1.24 \mathrm{~mm}-7.70 \mathrm{~mm}$, and the external maximum corrosion depth was associated with variations in the initial pipe thickness from $0.32 \mathrm{~mm}-5.71 \mathrm{~mm}$; these results show that the internal corrosion depth is greater than the external corrosion depth. It can therefore be judged that water has more influence than soil in terms of the corrosion of water supply pipes. The average internal maximum corrosion depth of the CIPs is $4.68 \mathrm{~mm}$ and the external maximum corrosion depth is $2.40 \mathrm{~mm}$, showing that the internal result is almost twice that of the external result. Also, in the distribution of the internal and external maximum corrosion depths according to laying year, as shown in Figure. 2, the corrosion depth varied depending on the laying year. It can be deduced that the corrosion of a water supply pipe worsens according to the laying year, while the water quality of the burial area or corrosiveness factors in the soil are also major influences. In the case of the DCIPs, the external maximum corrosion depth is from $0 \mathrm{~mm}-0.88 \mathrm{~mm}$ and the internal maximum corrosion depth is from $0 \mathrm{~mm}-1.89 \mathrm{~mm}$, as shown in Table 3. The final internal corrosion depth of the DCIPs was almost $0 \mathrm{~mm}$ because of the CML effect on the inside of the DCIPs. Also, a low external-corrosion-depth range is evident compared with the CIPs because of the short laying periods, whereby almost all of the DCIPs were buried after the 1980s in this city; therefore, the combined internal and external maximum corrosion depths of the CIPs is about 6 times greater than of the DCIPs, according to the data in Figure. 3

\section{Table 2. Results of Internal \& External Maximum Corrosion Depths and Residual Wall Thickness on CIP}

\begin{tabular}{ccccccc}
\hline Samples & $\begin{array}{c}\text { Laying } \\
\text { year }\end{array}$ & $\begin{array}{c}\text { Initial wall } \\
\text { thickness } \\
\text { of pipe } \\
(\mathrm{mm})\end{array}$ & $\begin{array}{c}\text { Internal } \\
\text { maximum } \\
\text { corrosion } \\
\text { depths of } \\
\text { pipe }(\mathrm{mm})\end{array}$ & $\begin{array}{c}\text { External } \\
\text { maximum } \\
\text { corrosion } \\
\text { depths of } \\
\text { pipe }(\mathrm{mm})\end{array}$ & $\begin{array}{c}\text { Corrosion } \\
\text { Index }\end{array}$ & $\begin{array}{c}\text { Residual } \\
\text { wall } \\
\text { thickness } \\
\text { of pipe } \\
\text { (mm) }\end{array}$ \\
\hline P-A-02 & 1968 & 10.5 & 2.68 & 2.81 & 0.52 & 5.02 \\
P-B-01 & - & 12 & 3.90 & 2.28 & 0.52 & 5.82 \\
P-B-02 & 1980 & 9.2 & 5.89 & 3.34 & 1.00 & 0.00 \\
P-B-03 & 1966 & 8.2 & 5.55 & 4.85 & 1.00 & 0.00 \\
P-B-05 & 1979 & 11.25 & 5.75 & 1.89 & 0.68 & 3.61 \\
P-C-03 & 1981 & 12.4 & 7.70 & 0.32 & 0.65 & 4.38 \\
P-C-04 & 1975 & 10.35 & 3.72 & 1.74 & 0.53 & 4.89 \\
P-D-01 & 1973 & 9.45 & 6.11 & 2.60 & 0.92 & 0.74
\end{tabular}




\begin{tabular}{ccccccc} 
P-D-03 & 1974 & 12.1 & 3.69 & 2.02 & 0.47 & 6.39 \\
P-D-05 & 1978 & 6.55 & 4.02 & 2.80 & 1.00 & 0.00 \\
P-D-08 & 1976 & 10.45 & 4.45 & 3.07 & 0.72 & 2.93 \\
P-D-09 & 1983 & 11.2 & 3.45 & 2.83 & 0.56 & 4.92 \\
P-D-11 & 1979 & 8.4 & 5.95 & 1.58 & 0.90 & 0.87 \\
P-D-13 & 1973 & 10.9 & 3.27 & 0.90 & 0.38 & 6.73 \\
P-E-02 & 1982 & 8.25 & 4.26 & 1.70 & 0.72 & 2.29 \\
P-E-04 & 1979 & 10.15 & 5.00 & 1.20 & 0.61 & 3.95 \\
P-E-05 & 1982 & 10.45 & 6.17 & 3.35 & 0.91 & 0.93 \\
P-F-01 & 1977 & 12.1 & 3.35 & 3.15 & 0.54 & 5.60 \\
P-F-03 & 1979 & 10.75 & 5.40 & 1.66 & 0.66 & 3.69 \\
P-F-09 & 1977 & 11.75 & 5.81 & 5.71 & 0.98 & 0.23 \\
P-F-14 & 1982 & 6.6 & 3.95 & 3.40 & 1.00 & 0.00 \\
P-F-17 & 1995 & 10.85 & 4.53 & 1.37 & 0.54 & 4.95 \\
P-F-19 & 1980 & 9.75 & 3.91 & 2.60 & 0.67 & 3.24 \\
P-F-20 & - & 9.2 & 3.70 & 0.83 & 0.49 & 4.67 \\
P-G-02 & 1981 & 10.35 & 5.89 & 2.10 & 0.77 & 2.36 \\
P-H-3 & 1990 & 11.4 & 6.90 & 4.48 & 1.00 & 0.02 \\
P-H-4 & 1982 & 9.05 & 1.24 & 1.63 & 0.32 & 6.18 \\
Average & 10.13 & 4.68 & 2.40 & 0.71 & 3.13 \\
\hline
\end{tabular}

\section{Table 3. Results of Internal \& External Maximum Corrosion Depths and Residual Wall Thickness on DCIP}

\begin{tabular}{rcccccc}
\hline Samples & $\begin{array}{c}\text { Laying } \\
\text { year }\end{array}$ & $\begin{array}{c}\text { Initial wall } \\
\text { thickness } \\
\text { of pipe } \\
(\mathrm{mm})\end{array}$ & $\begin{array}{c}\text { Internal } \\
\text { maximum } \\
\text { corrosion } \\
\text { depths of } \\
\text { pipe }(\mathrm{mm})\end{array}$ & $\begin{array}{c}\text { External } \\
\text { maximum } \\
\text { corrosion } \\
\text { depths of } \\
\text { pipe }(\mathrm{mm})\end{array}$ & $\begin{array}{c}\text { Corrosion } \\
\text { Index }\end{array}$ & $\begin{array}{c}\text { Residual } \\
\text { wall } \\
\text { thickness } \\
\text { of pipe } \\
(\mathrm{mm})\end{array}$ \\
\hline P-B-06 & - & 7.75 & 0.00 & 0.88 & 0.11 & 6.87 \\
P-E-10 & 1983 & 8.2 & 1.05 & 0.00 & 0.13 & 7.15 \\
P-F-11 & 1990 & 9.95 & 0.68 & 0.00 & 0.07 & 9.27 \\
P-F-13 & 1985 & 8.35 & 1.89 & 0.00 & 0.23 & 6.46 \\
P-F-18 & 1995 & 7.7 & 1.72 & 0.00 & 0.22 & 5.98 \\
P-I-01 & 1985 & 8.6 & 0.91 & 0.00 & 0.11 & 7.69 \\
P-I-06 & 1985 & 11 & 1.70 & 0.00 & 0.15 & 9.30 \\
Average & 8.79 & 1.14 & 0.13 & 0.15 & 7.53 \\
\hline
\end{tabular}

\subsection{Residual Thickness}

According to the residual thickness results of the CIPs and DCIPs in Table 2 and Table 3 , a small difference was expected for the CIPs because of the initial wall thicknesses of the pipes, but the CIPs are in the $0 \mathrm{~mm}-6.73 \mathrm{~mm}$ range and the DCIPs are in the 5.98 $\mathrm{mm}-9.30 \mathrm{~mm}$ range. Compared with the initial wall thicknesses of the pipes, the corrosion rate for the CIPs is $85.7 \%$ and it is $30.9 \%$ for the DCIPs. In this corrosion index (= the sum of internal and external maximum corrosion depths / initial wall thickness of pipe), the corrosion index of almost all of the CIPs is in the high range of $0.32-1.0$; it was therefore determined that the corrosion of most of the CIPs was significantly advanced. In contrast, the DCIPs had very low values of 0.07-0.23 compared with those of the CIPs. In accordance with the collected data in Figure 4., the corrosion index of the CIPs is 0.71, which is 4.7 times greater than 0.15 , the corrosion index of the DCIPs. 


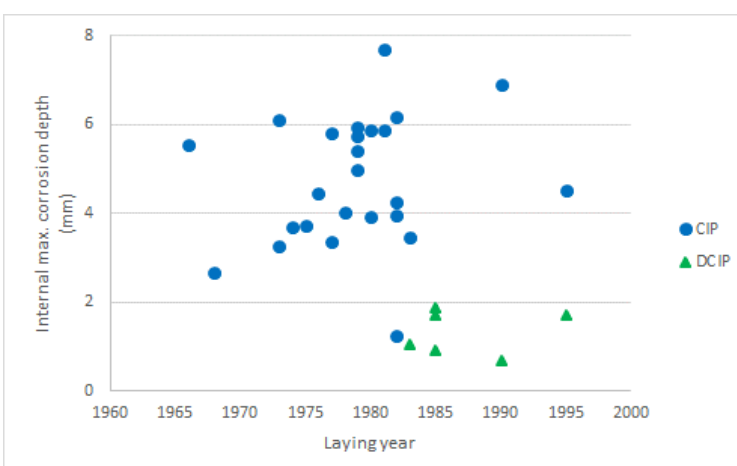

(a) Internal maximum corrosion depths of pipe

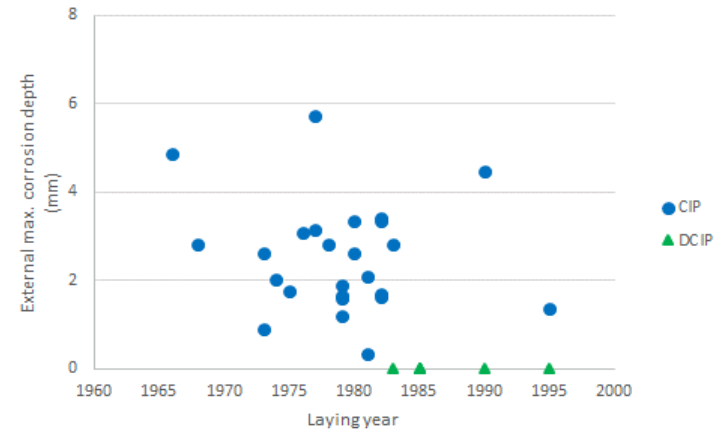

(b) External maximum corrosion depths of pipe

Figure 2. Distribution of Internal \& External Maximum Corrosion Depths of the CIPs and DCIPs

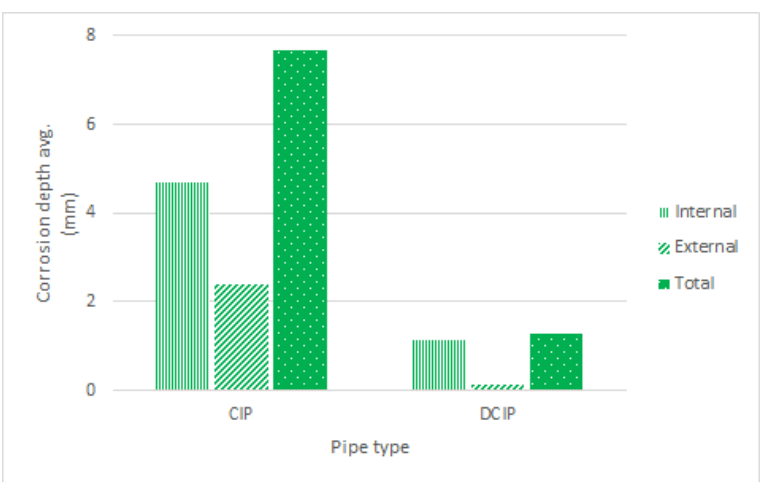

Figure 3. Comparison of Corrosion Depth Average on CIP and DCIP

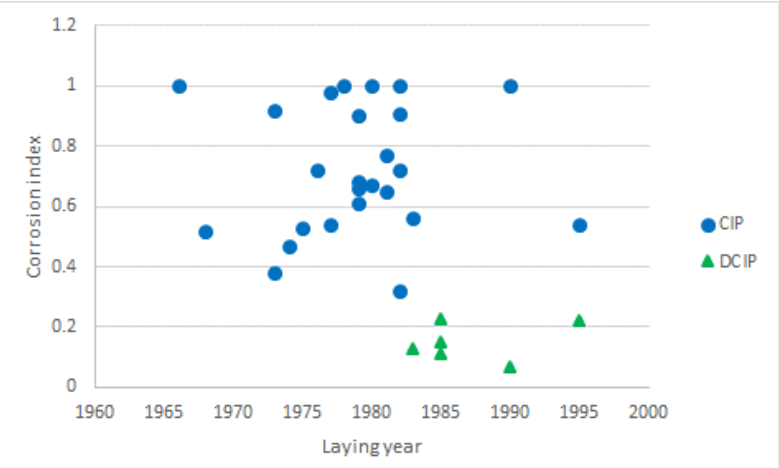

Figure 4. Distribution of Corrosion Index on CIP and DCIP 


\subsection{Corrosion Rate}

The results of the internal and external maximum corrosion rates collected for the CIPs and DCIPs in P city are shown in Table 4 and Table 5. In the tables, the internal maximum corrosion rate of the CIPs are from 0.07 mmpy- 0.69 mmpy and the external maximum corrosion rates of the CIPs are from $0.03 \mathrm{mmpy}-0.45 \mathrm{mmpy}$. These results show that the internal rate was higher than the external rate. On average, the internal maximum corrosion rate was 0.26 mmpy and the external maximum corrosion rate was $0.13 \mathrm{mmpy}$. It shows that the internal rate was twice as fast as the external rate. Also, according to Figure. 5, regarding the relationship between the distribution of internal and external maximum corrosion rates and the laying year, the corrosion rate increased slightly in accordance with the shortening of the period since the laying year. This corrosion of the water supply pipes increased rapidly in the early years after laying according to the laying year, while the more that the period since the laying year increased, the more that the corrosion rate decreased. The maximum corrosion rate as the sum of the internal and external maximum corrosion rates within Figure. 6 show that the CIPs laid before 1975 are in the 0.15 mmpy-0.32 mmpy range, those laid between 1976 and 1985 are in the 0.16 mmpy- 0.53 mmpy range, and the 2 pipes laid after 1985 are in the 1.14 mmpy-1.18 mmpy range; this shows that the CIPs laid most recently had the highest corrosion rates. For the DCIPs in Table 5, the internal corrosion rates that are represented as 0.00 mmpy regardless of the laying year indicate that corrosion did not proceed. In contrast, the external maximum corrosion rates were indicated in the 0.06 mmpy-0.34 mmpy range, but its rate was very low compare with the CIPs maximum corrosion rate. In Figure 7, the maximum corrosion rate of the CIPs in P city was relatively high compared with that of the DCIPs on more than 3 occasions.

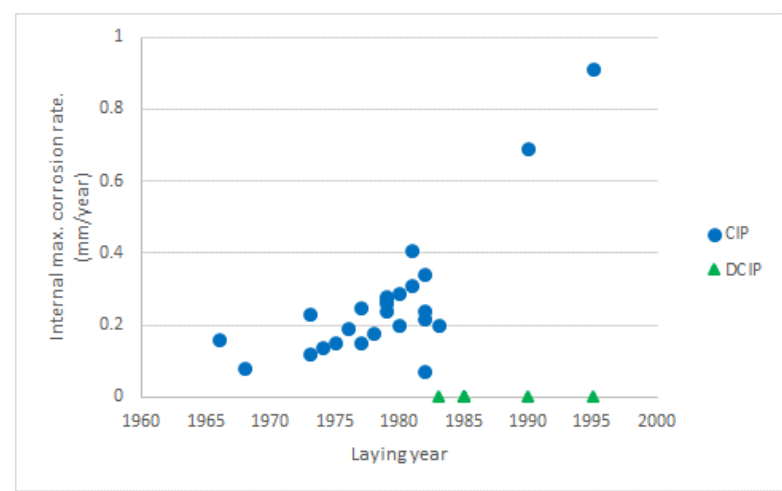

(a) Internal maximum corrosion rates

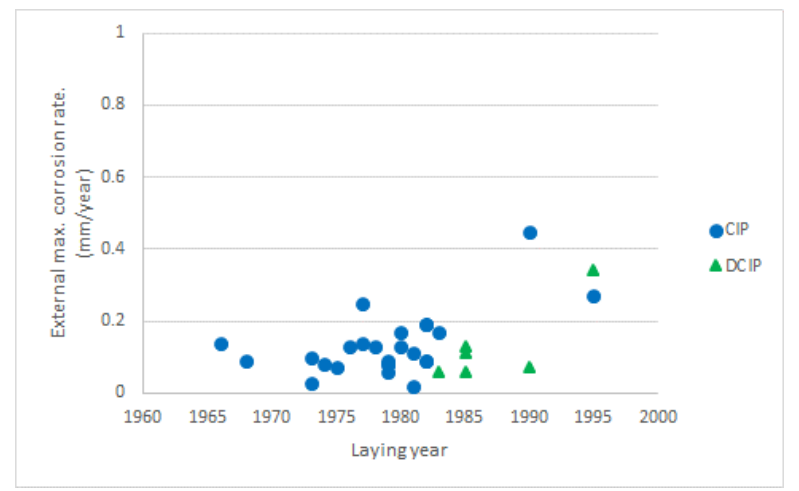

(b) External maximum corrosion rates

Figure 5. Distribution of Internal \& External Maximum Corrosion Rates 


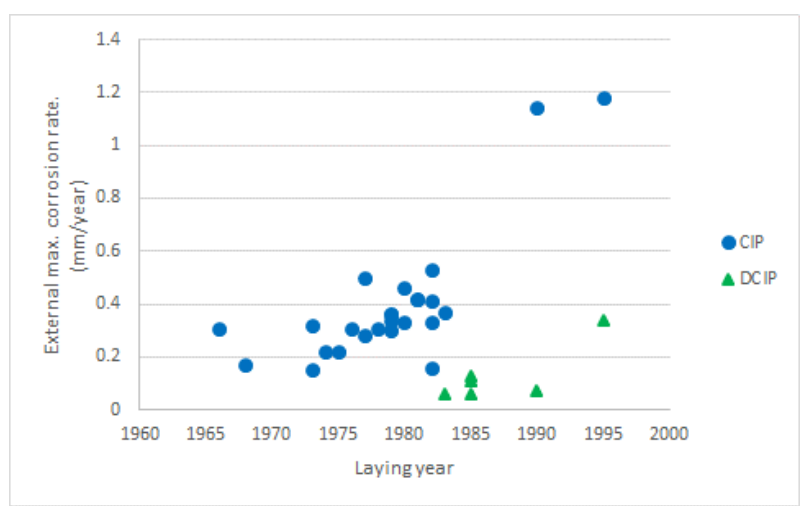

Figure 6. Distribution of Maximum Corrosion Rates

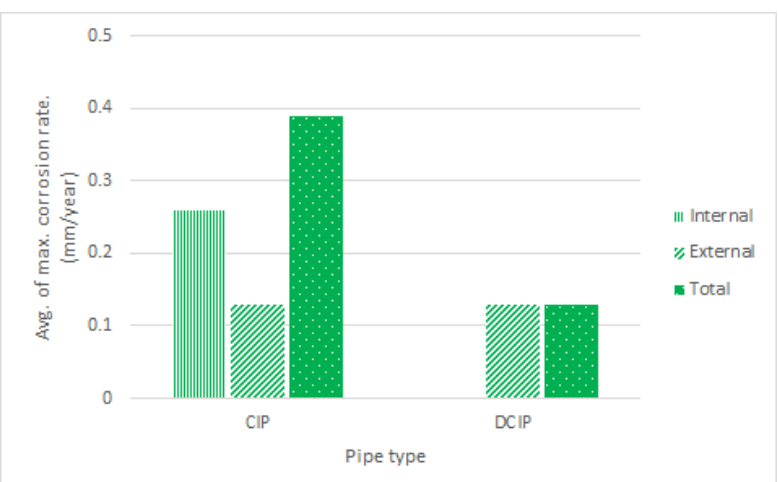

Figure 7. Comparison of Corrosion Rate on CIP and DCIP

Table 4. Results of Internal \& External Maximum Corrosion Rates on CIP

\begin{tabular}{lccccc}
\hline Samples & $\begin{array}{c}\text { Pipe } \\
\text { type }\end{array}$ & $\begin{array}{c}\text { Laying } \\
\text { year }\end{array}$ & $\begin{array}{c}\text { Internal maximum } \\
\text { corrosion rate of } \\
\text { pipe } \\
\text { (mm/year) }\end{array}$ & $\begin{array}{c}\text { External maximum } \\
\text { corrosion rate of } \\
\text { pipe }\end{array}$ & $\begin{array}{c}\text { Maximum } \\
\text { corrosion rate } \\
\text { (mm/year) }\end{array}$ \\
\hline P-A-02 & CIP & 1968 & 0.08 & 0.09 & 0.17 \\
P-B-02 & CIP & 1980 & 0.29 & 0.17 & 0.46 \\
P-B-03 & CIP & 1966 & 0.16 & 0.14 & 0.31 \\
P-B-05 & CIP & 1979 & 0.27 & 0.09 & 0.36 \\
P-C-03 & CIP & 1981 & 0.41 & 0.02 & 0.42 \\
P-C-04 & CIP & 1975 & 0.15 & 0.07 & 0.22 \\
P-D-01 & CIP & 1973 & 0.23 & 0.10 & 0.32 \\
P-D-03 & CIP & 1974 & 0.14 & 0.08 & 0.22 \\
P-D-05 & CIP & 1978 & 0.18 & 0.13 & 0.31 \\
P-D-08 & CIP & 1976 & 0.19 & 0.13 & 0.31 \\
P-D-09 & CIP & 1983 & 0.20 & 0.17 & 0.37 \\
P-D-11 & CIP & 1979 & 0.28 & 0.08 & 0.36
\end{tabular}




$\begin{array}{llllll}\text { P-D-13 } & \text { CIP } & 1973 & 0.12 & 0.03 & 0.15 \\ \text { P-E-02 } & \text { CIP } & 1982 & 0.24 & 0.09 & 0.33 \\ \text { P-E-04 } & \text { CIP } & 1979 & 0.24 & 0.06 & 0.30 \\ \text { P-E-05 } & \text { CIP } & 1982 & 0.34 & 0.19 & 0.53 \\ \text { P-F-01 } & \text { CIP } & 1977 & 0.15 & 0.14 & 0.28 \\ \text { P-F-03 } & \text { CIP } & 1979 & 0.26 & 0.08 & 0.34 \\ \text { P-F-09 } & \text { CIP } & 1977 & 0.25 & 0.25 & 0.50 \\ \text { P-F-14 } & \text { CIP } & 1982 & 0.22 & 0.19 & 0.41 \\ \text { P-F-17 } & \text { CIP } & 1995 & 0.91 & 0.27 & 1.18 \\ \text { P-F-19 } & \text { CIP } & 1980 & 0.20 & 0.13 & 0.33 \\ \text { P-G-02 } & \text { CIP } & 1981 & 0.31 & 0.11 & 0.42 \\ \text { P-H-3 } & \text { CIP } & 1990 & 0.69 & 0.45 & 1.14 \\ \text { P-H-4 } & \text { CIP } & 1982 & 0.07 & 0.09 & 0.16 \\ & \text { Average } & & 0.26 & 0.13 & 0.40\end{array}$

Table 5. Results of Internal \& External Maximum Corrosion Rates on DCIP

\begin{tabular}{cccccc}
\hline Samples & $\begin{array}{c}\text { Pipe } \\
\text { type }\end{array}$ & $\begin{array}{c}\text { Laying } \\
\text { year }\end{array}$ & $\begin{array}{c}\text { Internal maximum } \\
\text { corrosion rate of } \\
\text { pipe } \\
(\mathrm{mm} / \text { year })\end{array}$ & $\begin{array}{c}\text { External maximum } \\
\text { corrosion rate of } \\
\text { pipe }\end{array}$ & $\begin{array}{c}\text { Maximum } \\
\text { corrosion rate } \\
(\mathrm{mm} / \text { year })\end{array}$ \\
\hline P-E-10 & DCIP & 1983 & 0.00 & 0.06 & 0.06 \\
P-F-11 & DCIP & 1990 & 0.00 & 0.07 & 0.07 \\
P-F-13 & DCIP & 1985 & 0.00 & 0.13 & 0.13 \\
P-F-18 & DCIP & 1995 & 0.00 & 0.34 & 0.34 \\
P-I-01 & DCIP & 1985 & 0.00 & 0.06 & 0.06 \\
P-I-06 & DCIP & 1985 & 0.00 & 0.11 & 0.11 \\
& Average & & 0.00 & 0.13 & 0.13 \\
\hline
\end{tabular}

\subsection{Neutralization Rate}

The neutralization percentages, neutralization rates, and the tn estimated after complete neutralization for the DCIPs collected from P city are shown in Table 6. From the table, the neutralization percentages of the DCIPs from P city were in the 10\%-100\% range, with average neutralization at $52 \%$. The neutralization rate is in the range of $1.00 \% / y e a r-$ $6.67 \% / y e a r$, with an average of 3.65\%/year. So, it concluded that all CML neutralized before and after 27 years on average in P city. 
Table 6. CML-N ratio and rate of CML Neutralization

\begin{tabular}{cccccc}
\hline Samples & $\begin{array}{c}\text { Pipe } \\
\text { type }\end{array}$ & $\begin{array}{c}\text { Laying } \\
\text { year }\end{array}$ & CML-N ratio* & $\begin{array}{c}\text { Rate of CML neutralization } \\
(\% / y e a r)\end{array}$ & $\begin{array}{c}\mathrm{t}_{\mathrm{n}} \\
\text { (year) }\end{array}$ \\
\hline P-E-10 & DCIP & 1983 & 100 & 5.88 & 0.00 \\
P-F-11 & DCIP & 1990 & 10 & 1.00 & 90.00 \\
P-F-13 & DCIP & 1985 & 50 & 3.33 & 15.00 \\
P-F-18 & DCIP & 1995 & 10 & 2.00 & 45.00 \\
P-I-01 & DCIP & 1985 & 50 & 3.33 & 15.00 \\
P-I-06 & DCIP & 1985 & 50 & 3.33 & 15.00 \\
\hline
\end{tabular}

*CML-N ratio : Neutralization ratio of cement mortar lining.

\subsection{Estimation of Residual Life}

In general, it is possible to estimate residual life by dividing the residual thickness by the maximum corrosion rate; however, great differences in the maximum corrosion rate have been observed in accordance with the laying year and those pipes laid more recently have a higher maximum corrosion rate. For water supply pipes with a recent laying year, there is a concern that the estimated residual life is relatively low; therefore, the diminishing of the maximum corrosion rate according to the laying year should be considered to estimate residual life accurately in the future.

Accordingly, the periods of time since the laying year were divided into 5-year blocks for the collected CIPs to calculate the relationship with the maximum corrosion rate, as shown in Figure. 8. The 5-year blocks were then divided according to 6 steps, as shown in Table 7, to calculate the maximum corrosion rate of each step and the effect of an increasing period since the laying year. However, the CIPs tended to have a short residual life because the corrosion rates of the pipes were overestimated as relatively low, rather than what is indicated by the maximum corrosion rates in Table 4. In this study, the residual life was therefore estimated by applying the maximum corrosion rates shown in Table 4, called $\mathrm{R}_{\mathrm{lf}}$, and was calculated by adjusting the maximum corrosion rate at each step according to the laying years shown in Table 7 , called $\mathrm{R}_{\mathrm{If} 2}$; therefore, the final residual life was determined as $\mathrm{R}_{\mathrm{lf}}$ by using $\operatorname{MAX}\left(\mathrm{R}_{\mathrm{lf} 1}: \mathrm{R}_{\mathrm{lf} 2}\right)=\mathrm{R}_{\mathrm{lf}}$.

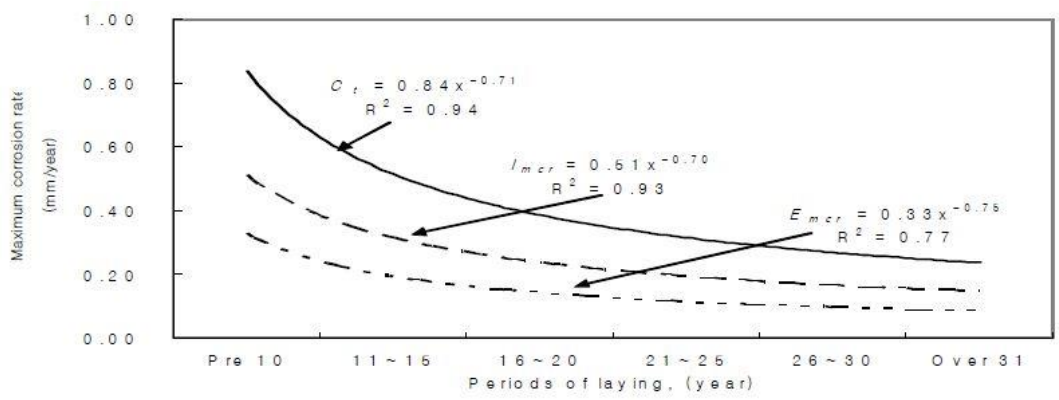

Figure 6. Distribution of Maximum Corrosion Rates

For DCIPs which are laid more recently, only the external corrosion rate applied in an estimation of the residual life before the neutralization of the CML, but both the internal and external rates, obtained from Table 7, applied after neutralization. The final residual results of the CIPs and DCIPs in P city are shown in Table 8 and Table 9. 
From the table, the residual life of the CIPs in P city are in the 0 year-44 year range, with an average 12.40 years; therefore, for $\mathrm{P}$ city, it is necessary to plan rehabilitative and replacement work due to the very short residual life of nearly all of the CIPs.

That is, penetration from water-supply-pipe corrosion does not always occur when the residual life is 0 because pipes that are buried underground are forced to withstand high soil pressure externally and high water pressure internally.

Table 7. Maximum Corrosion Rate modified by Figure. 8

\begin{tabular}{ccccc}
\hline Step & Laying year & $\begin{array}{c}\text { Internal maximum } \\
\text { corrosion rate of } \\
\text { pipe } \\
\text { (mm/year) }\end{array}$ & $\begin{array}{c}\text { External maximum } \\
\text { corrosion rate of } \\
\text { pipe }\end{array}$ & $\begin{array}{c}\text { Maximum } \\
\text { corrosion rate } \\
\text { (mm/year) }\end{array}$ \\
\hline I & Pre 10 & 0.51 & 0.33 & 0.84 \\
II & $11-15$ & 0.31 & 0.20 & 0.51 \\
II & $16-20$ & 0.24 & 0.14 & 0.39 \\
IV & $21-25$ & 0.19 & 0.12 & 0.31 \\
V & $26-30$ & 0.17 & 0.10 & 0.27 \\
VI & & & & 0.24 \\
\hline
\end{tabular}

Table 8. Prediction of Residual Life on CIP of P city

\begin{tabular}{cccccccc}
\hline Samples & $\begin{array}{c}\text { Pipe } \\
\text { type }\end{array}$ & $\begin{array}{c}\text { Laying } \\
\text { year }\end{array}$ & $\begin{array}{c}\text { Periods of } \\
\text { laying } \\
\text { (year) }\end{array}$ & $\begin{array}{c}\text { Residual life of pipe (year) } \\
\text { R }\end{array}$ & $\begin{array}{c}\text { Total life } \\
\text { of pipe } \\
\text { (year) }\end{array}$ \\
\hline P-A-02 & CIP & 1968 & 32 & 29 & 21 & 29 & 61 \\
P-B-02 & CIP & 1980 & 20 & 0 & 0 & 0 & 20 \\
P-B-03 & CIP & 1966 & 34 & 0 & 0 & 0 & 34 \\
P-B-05 & CIP & 1979 & 21 & 10 & 13 & 13 & 34 \\
P-C-03 & CIP & 1981 & 19 & 10 & 16 & 16 & 35 \\
P-C-04 & CIP & 1975 & 25 & 22 & 20 & 22 & 47 \\
P-D-01 & CIP & 1973 & 27 & 2 & 3 & 3 & 30 \\
P-D-03 & CIP & 1974 & 26 & 29 & 26 & 29 & 55 \\
P-D-05 & CIP & 1978 & 22 & 0 & 0 & 0 & 22 \\
P-D-08 & CIP & 1976 & 24 & 9 & 11 & 11 & 35 \\
P-D-09 & CIP & 1983 & 17 & 13 & 17 & 17 & 34 \\
P-D-11 & CIP & 1979 & 21 & 2 & 2 & 2 & 23
\end{tabular}




\begin{tabular}{llllcccc} 
P-D-13 & CIP & 1973 & 27 & 44 & 28 & 44 & 71 \\
P-E-02 & CIP & 1982 & 18 & 7 & 6 & 7 & 25 \\
P-E-04 & CIP & 1979 & 21 & 13 & 15 & 15 & 36 \\
P-E-05 & CIP & 1982 & 18 & 2 & 2 & 2 & 20 \\
P-F-01 & CIP & 1977 & 23 & 20 & 22 & 22 & 45 \\
P-F-03 & CIP & 1979 & 21 & 11 & 14 & 14 & 35 \\
P-F-09 & CIP & 1977 & 23 & 0 & 1 & 1 & 24 \\
P-F-14 & CIP & 1982 & 18 & 0 & 0 & 0 & 18 \\
P-F-17 & CIP & 1995 & 5 & 4 & 6 & 6 & 11 \\
P-F-19 & CIP & 1980 & 20 & 10 & 11 & 11 & 31 \\
P-G-02 & CIP & 1981 & 19 & 6 & 7 & 7 & 25 \\
P-H-3 & CIP & 1990 & 10 & 0 & 0 & 0 & 10 \\
P-H-4 & CIP & 1982 & 18 & 39 & 22 & 39 & 57 \\
& Average & & 21.16 & 11.28 & 10.52 & 12.40 & 33.52 \\
\hline
\end{tabular}

Table 9. Prediction of Residual Life on DCIP of P city

\begin{tabular}{ccccccc}
\hline Samples & $\begin{array}{c}\text { Pipe } \\
\text { type }\end{array}$ & $\begin{array}{c}\text { Laying } \\
\text { year }\end{array}$ & $\begin{array}{c}\text { Periods of } \\
\text { laying } \\
\text { (year) }\end{array}$ & $\begin{array}{c}\mathrm{t}_{\mathrm{n}} \\
\text { (year) }\end{array}$ & $\begin{array}{c}\text { Residual life of } \\
\text { pipe, } \mathrm{R}_{\mathrm{If} 1} \\
\text { (year) }\end{array}$ & $\begin{array}{c}\text { Total life of } \\
\text { pipe } \\
\text { (year) }\end{array}$ \\
\hline P-E-10 & DCIP & 1983 & 17 & 0.00 & 14 & 31 \\
P-F-11 & DCIP & 1990 & 10 & 90.00 & 95 & 105 \\
P-F-13 & DCIP & 1985 & 15 & 15.00 & 24 & 39 \\
P-F-18 & DCIP & 1995 & 5 & 45.00 & 41 & 46 \\
P-I-01 & DCIP & 1985 & 15 & 15.00 & 28 & 43 \\
P-I-06 & DCIP & 1985 & 15 & 15.00 & 29 & 44 \\
& Average & & 12.83 & 30.00 & 38.50 & 51.33 \\
\hline
\end{tabular}

An improvement plan should therefore be established to improve the leakageprevention capacity of water supply pipes before the end of the residual lives. Also, for P$\mathrm{H}-3$, the residual life was very short even though it was buried recently, and for P-A-02, 32 years had passed since the laying year but its residual life was estimated at 29 years. It is therefore more economic and efficient to prevent leakage by properly estimating the residual life of a water supply pipe instead of using the existing improvement plan, whereby only the laying year and the age of the pipe are considered.

In Table 8, the total life years is the sum of the duration since the laying year and the residual life. For CIPs in P city, the estimated average total life is 33.52 years, indicating that only one-third of the total life years remain for the CIPs in P city.

For the DCIPs shown in Table 9, the average residual life is 38.50 years, which is 3 times higher than that of the CIPs, and the total life year estimate is 51.33 years; therefore, one-half of the total life years remain for the DCIPs in P city. The total life of the DCIPs in $\mathrm{P}$ city is approximately 1.5 times longer than that of the CIPs in P city; however, the 
improvement of the DCIPs should be completed before the neutralization of the CML due to the rapid procession of internal corrosion after neutralization.

\section{Acknowledgements}

This study was supported by the main project "Development of Water Distribution Technology in Microgrid" of the Korea Institute of Civil Engineering and Building Technology.

\section{References}

[1] Water Supply Statistics (2013), Ministry of Environment, (2014).

[2] H. D. Lee, "Development of Pipe Corrosion Assessment Model In Water Distribution Systems", Korea Society Environmental Engineers Autumn Conference collection of papers ( I), (2000), pp.485-486.

[3] H. D. Lee, "Development of Prediction Model of Corrosion Status and Pipe Deterioration in Water Distribution Systems", G-7 Environmental Engineers Project of Technology Development, Ministry of Environment, (2002).

[4] H. D. Lee, "Characteristics of Water Quality Parameters on Enhancing and Inhibiting Corrosion in Water Distribution Systems", Korea Society Environmental Engineers, vol.20, no.8, (1998), pp.11511160 .

\section{Authors}

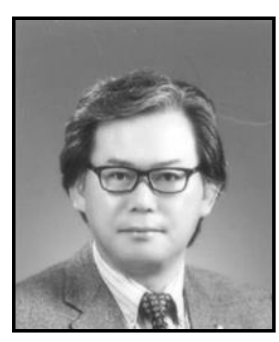

\section{Lee Hyun-dong}

ACADEMIC BACKGROUND:

Oct 1993, Kyoto University, Post-Ph.D in Environmental Engineering.

Aug 1991, Hanyang University

Ph.D in Civil and Environmental Engineering

Feb 1987, Hanyang University

MS in Civil and Environmental Engineering

PROFESSIONAL EXPERIENCE:

Sep 2007 , Korea University of Science \& Technology, Professor with Department of Construction \& Environment Engineering

Dec 2004 Dec 2005, The University of Iowa, Visiting Professor with Department of Civil \& Environmental Engineering

Jul 1987 , Korea Institute of Civil Engineering and Building Technology, Senior Research Fellow, Environmental Engineering Research Department

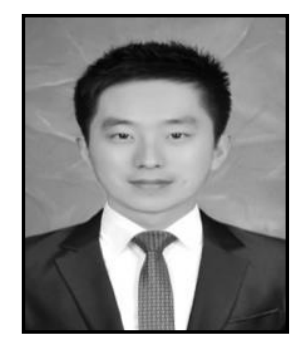

\section{Shin Hong-Cheol}

ACADEMIC BACKGROUND:

Feb 2012, Kookmin University

$\mathrm{BD}$ in Civil and Engineering 